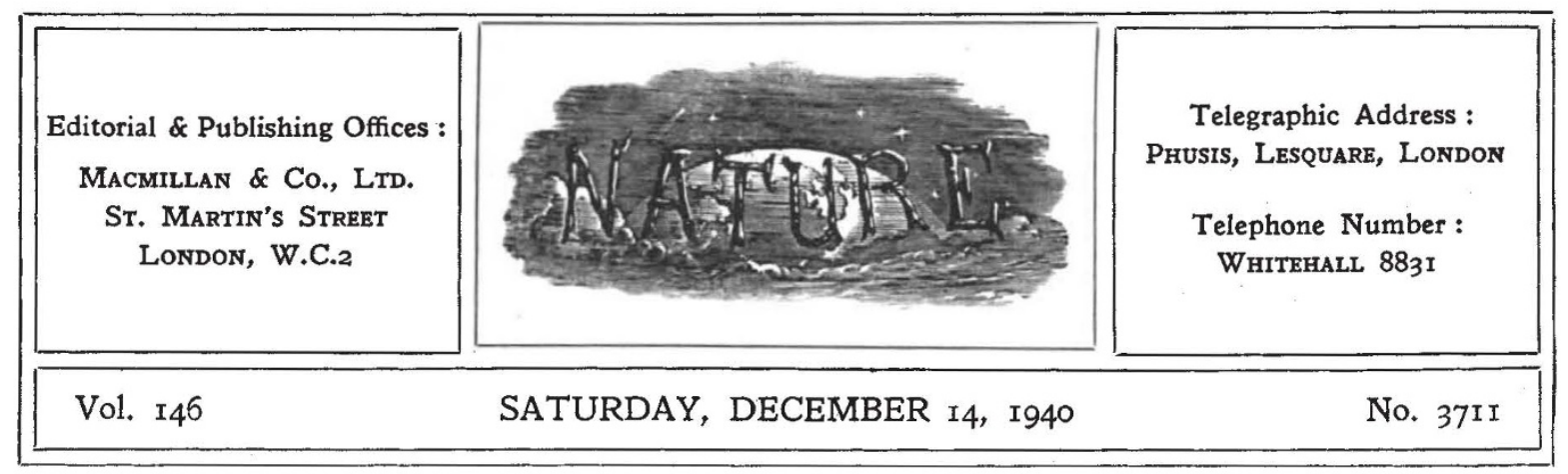

\title{
SCIENTIFIC SOCIETIES IN WAR-TIME
}

$\mathrm{I}^{\mathrm{N}}$ $\mathrm{N}$ times of peace London is unquestionably the focus of the scientific life of the British nation and Commonwealth. The reason is not that London is the seat of the metropolitan university, though this, by its system of external degrees, is also in a special sense the central university of the Empire ; moreover, it enfolds within itself many special institutions, like the Schools of Economics and of Hygiene and Tropical Medicine, which are themselves imperial centres for special branches of science. Nor is it that London is the seat of the chief national scientific departments, like that of Scientific and Industrial Research, or the Medical and Agricultural Research Councils. London had attained its position as the national scientific centre long before these modern bodies had been constituted, and before the University of London had come to be comparable, in size and influence, with the older Universities of Oxford and Cambridge (though as a centre of medical teaching London had long been pre-eminent). During two centuries and more in which the venerable sister Universities were still unrivalled except by each other, as centres of learning and research, their scientific members found a common meeting ground in London, in the rooms of the Royal Society : and during the nineteenth century London became the centre also of many more specialized scientific societies.

The relatively small size of the British Isles, and the excellence of their railway communications, make it conveniently possible for those who follow any special branch of science to come together, from all parts of Great Britain, to meet in London several times yearly. In this respect British men of science have an advantage not enjoyed by their colleagues in greater and more widespread com- munities like those of the Dominions, the United States, the U.S.S.R., or even Germany. In these countries regional centres have consequently developed, and national meetings tend to be annual and peripatetic, like those of the British Association. Such regional centres flourished also in Great Britain in the days before speedy travel became possible, but except in Dublin and Edinburgh they seldom attained the distinction of some of the principal academies of Germany, and with few exceptions they have declined since the days, for example, when Dalton was the glory of the Manchester Literary and Philosophical Society. Some of the chief British technical scientific societies, however, have in modern times developed valuable regional activities, in centres where meetings are held in addition to those at their main headquarters in London.

While the present War was still only a threatening possibility, the controlling bodies of some of the national scientific societies tried to prepare for future eventualities by arranging for the transfer of their offices from London, the safeguarding of their most cherished property, and alternative arrangements for meetings, in case the expected Blitzkrieg on London became a reality. On the outbreak of the War, some of these plans were carried out; in other cases the councils of the scientific societies met to consider whether or not their pre-arranged series of meetings should be held. There were pessimists who thought it would be useless and undesirable to hold meetings, because of the absence, or absorption in war work, of many members, including some of the leading personalities. But in the main such counsels were not followed, and many societies held their meetings as usual throughout the session, from October 
or November until June, during the unexpectedly prolonged immunity of London from aerial attack. Towards the end of the 1939-1940 session, some of the societies reverted partly to their pre-War condition, by the return of their offices and staff to London, or by the partial reopening of their premises or library. Even through the dark days of the over-running of Norway, Denmark, Holland and Belgium, followed by the ominous signs of weakness that preceded the collapse of France, much of the scientific life of London was maintained: At the beginning of the summer recess there seemed hope that if the threatened invasion were forestalled or repelled, the autumn might see a resumption of London scientific meetings, little changed except for some decline in the numbers of those attending and of the papers presented.

In August, however, the long-postponed air attack fell upon London, and before the usual date of reassembly of the scientific societies, daily and nightly raids became a regular feature of London life. The question of the continuance of meetings has now acquired a more serious and perhaps controversial aspect in the new circumstances. Not only has the 'black-out' assumed if anything a deeper tinge than before, but also interruption and dislocation of road and rail transport has been caused from time to time by the enemy bombing. Especially after darkness has fallen and night raids have begun, travel is difficult and unpleasant, and late afternoon meetings, which in winter fall during the hours of darkness, are for this reason likely to attract few attenders. Still less likely is it that members would continue to stay to club dinners after such meetings, though in peace-time such dinners form a useful and pleasant supplement to the formal gatherings of the scientific societies.

The safest course would naturally be to discontinue meeting at all, at least during the darkest months of the winter. As a set-off against such a lapse in the ordinary activity of the societies, the sessions might be prolonged into what is in normal times the summer vacation, but which in these years of shortened or suspended holidays would be fully appropriate for scientific meetings. Some societies have already suspended their usual winter meetings, with or without an indication of the expected date of their resumption.

Others, bolder and (in the judgment of some) more admirable, are continuing to meet in London, either as usual or at an earlier hour, so that the meeting may be concluded before nightfall. In some quarters the holding of the regular meetings outside London has been considered, but except where societies have developed regional activities and centres in peace-time, it seems unlikely that such meetings would be so successful as afternoon meetings in London would be; this is partly because it remains much easier to travel to than any other centre, from places more than a few miles away, and partly because London and the surrounding counties still contain the largest number of potential visitors to scientific meetings. To those who live at a distance, in regions that have not suffered serious air attacks, it may seem to be merely foolish bravado to propose that scientific men should foregather in London; it should be remembered, however, that the millions of people who continue to inhabit the London area include many who would welcome scientific meetings not less than in peace-time, and who would feel no more in danger at such meetings than in any of the other places, of work or dwelling or recreation, which they frequent. This is perhaps insufficiently considered by some council members of scientific societies who, for whatever reasons, being unable or not wishing themselves to take part in such meetings, lend their influence to abandonment or postponement.

A more fundamental objection to the continuance or resumption of the winter scientific programme is raised in some quarters, as it was also in the War of 1914-18 - that scientific meetings are intrinsically unjustifiable in war-time, being a misuse of hours that ought to be devoted to definite war work. This view ignores the fact that there are still many scientific workers, capable of helping to overcome our enemies, and anxious to be thus used, whose services have not been called upon, or have even been declined when offered. But even as regards those whose time is actively occupied in scientific war work, the oriticism seems answerable. Neither manual nor intellectual workers can work all their waking hours; some leisure and refreshment of mind are necessary to enable a man to do his best work ; and the solution of a pressing war problem may be facilitated, not retarded, by a break in the routine hours of labour, and by meeting with colleagues who share similar peace-time scientific interests, whether or not they are likewise now engaged in war service.

Almost all the general arguments that justify the expenditure of time and travel involved in attendance at scientific meetings in peace-time remain valid also in war-time. Just as a Christian 
finds no less need now than in normal days to assemble in church with his fellow worshippers, so the man of science still needs to maintain his contacts with fellow workers and with scientific progress outside his own special activity. War is not exclusively a matter of the organization and execution of material defence and attack; the mind no less than the body and the spirit must be kept in sound condition in order to continue to develop these material measures.

The officers of scientific societies, however, doubtless find other obstacles to meeting than those of risk and travel difficulties. The work of scientific technicians is now largely directed to war problems the solutions of which must for the present be kept secret; and so many workers in pure science are now drafted into the technical defence services that the output of pure research which can be safely published in war-time is much reduced. These factors are in one way a help to societies, in reducing the pressure on their resources of money (and of paper) for publications ; but unless the societies are to fall into a state of suspended animation that may seriously prejudice their future revival, some degree of publication must be continued. The volume and perhaps even the standard of the papers published and read may be somewhat reduced, but the sources are scarcely likely to dry up entirely ; and a shortage of papers for reading at meetings can be eked out partly by a moderate reduction in the length of the meetings, and also by arranging discussions, a course which has been so successfully followed by the Royal Society in recent years.

\section{ENTOMOLOGY OF STORED PRODUCTS}

\section{Insect Pests in Stored Products}

By H. Hayhurst. Pp. xii $+83+49$ plates. (London: Chapman and Hall, Ltd., 1940.) 15s. net.

$A \mathrm{~S}$ a guide to the industrial chemist desirous $A$ of learning something of the appearance and mode of occurrence of the insect and arachnid pests of stored products this book is useful. The excellent illustrations by Mr. Harry Britten are numerous, the description of the insects is reasonably adequate, and the emphasis laid on cleanliness in stores and in vehicles of transport is sound. A list of "substances and their pests" is given as an appendix to the book' and there is a short index of contents. The inclusion of the moths Plodia and Ephestia among the "substances" as "subject to attack" by the parasitic wasp Habrobracon is amusing.

Doubtless this book is, as Sir Harold Hartley points out in a foreword, intended for the industrial chemist. It is to be regretted that the author did not amplify on one hand, and simplify on the other, to meet the needs of warehouse managers, foremen and others who are the parties immediately concerned with infestation. While it is useful to have short descriptions of the insects infesting stores and warehouses, together with short accounts of the products on which they commonly occur, collected into a single small handbook, the most urgent need in combating insect infestation of food and other stores is a better understanding of how infestation occurs, and how it may attain an alarming extent and how only organized and concerted action can really cope with it. These matters are not discussed.
To the reader conversant with the literature, Mr. Hayhurst's sources of information are obvious ; but he might have acknowledged them, including the source of material for Mr. Britten's illustra. tions, and in doing so have enabled his colleagues in the railway companies and elsewhere to read for themselves what is known of their problems and to keep in touch with the rapid progress in the understanding of them and towards their solution which is now being made. The early work of the Empire Marketing Board in this field is wholly ignored, although in his preface Mr. T. W. Jones refers to the subsequent work of the British Association of Research for the Cocoa, Chocolate, Sugar, Confectionery and Jam Trades. The work. of Drs. Page and Lubatti in the science and practice of fumigation is not even mentioned. The great improvement in insecticides for use in warehouses, achieved by Dr. Charles Potter, is referred to ; but no mention is made of any of his papers on the subject, which are of high importance, both scientifically and practically.

It is a real defect in Mr. Hayhurst's book that no bibliography of the subject is given. The cost of the book is high, and, in the absence of references to sources of information whereby the reader could extend his knowledge, excessive.

One comment on Mr. Hayhurst's book may be made. It illustrates very well how, outside the research laboratories, the entomology of stored products is still in that early stage of development where description of the insects concerned and general recommendations about their control represent the knowledge apparently acceptable and 